\title{
ARBORIZAÇÃO URBANA EM QUADRAS DE DIFERENTES PADRÕES CONSTRUTIVOS NA CIDADE DE JATAÍ ${ }^{1}$
}

\begin{abstract}
Elaine Franciely Santos Barros², Frederico Augusto Guimarães Guilherme ${ }^{3}$ e Raquel dos Santos Carvalho $^{4}$

RESUMO - O objetivo deste trabalho foi avaliar comparativamente a qualidade e quantidade de árvores plantadas no perímetro urbano da cidade de Jataí, GO. Para possibilitar as comparações foi utilizado um mapa georreferenciado de todas as quadras da cidade de Jataí, as quais foram subdividas em três categorias, de acordo com o padrão de construção civil adotado: 1. alto/médio, 2. simples e 3. precário. Em cada categoria foi avaliada a arborização urbana de 60 quadras, escolhidas aleatoriamente no mapa, independentemente do bairro. Foram encontrados 1.953 indivíduos, sendo 1.853 de espécies exóticas e 100 de espécies nativas, totalizando 114 espécies, sendo a mais utilizada na arborização o oiti (Licania tomentosa), com 31\% de todos os indivíduos. O número médio de árvores foi significativamente maior nos padrões alto/médio e simples do que no padrão precário. Com relação à posição na calçada, o padrão alto/médio apresentou melhor adequação de plantio. Espécies de médio e pequeno portes, bem como palmeiras, foram encontradas em maior quantidade no padrão alto/médio. Este estudo mostrou claras discrepâncias na arborização urbana da cidade em relação aos padrões construtivos. Dessa forma, os resultados podem subsidiar técnicos da Prefeitura Municipal de Jataí, bem como a população, no sentido de instruir desde a melhor forma de plantio e escolha de mudas apropriadas até a manutenção delas após a maturação.
\end{abstract}

Palavras-chave: Arborização urbana, Inventário de arborização e Paisagismo urbano.

\section{URBAN ARBORIZATION IN BLOCKS OF DIFFERENT BUILDING PATTERNS IN JATAÍ CITY}

\begin{abstract}
The study aimed to comparatively evaluate the quality and quantity of tree planting in the urban perimeter of Jataí city, Brazilian central region. To make comparisons possible, a georeferenced map of all blocks in the city was used. These were partitioned into three categories by the building parameters, denominated 1. high/medium, 2. simple and 3. precarious patterns. For each category the urban arborization of 60 blocks, randomly selected on the map, independent of the quarter was evaluated. The survey detected 114 different species and 1953 trees, distributed into 1853 exotic and 100 native species. Oiti (Licania tomentosa) was the more common species used in arborization, with $31 \%$ of all trees surveyed. The tree average number was significantly higher in high/medium and simple patterns than the precarious pattern. When considering the sidewalk position, the high/medium pattern showed the greatest adjustments in planting. Medium and small tree weight species and palm trees were more abundant in high/medium patterns. This study showed evident differences in urban arborization between categories compared to the streets of the Jataí city. Thus, the results can allow and technically instruct the prefecture, as well as the entire population of this city about forms of better planting, choices of appropriate seedlings and maintenance until maturity.
\end{abstract}

Keywords: Urban planting, Tree survey and Landscaping.

\footnotetext{
${ }^{1}$ Recebido em 21.04.2008 e aceito para publicação em 14.10.2009.

${ }^{2}$ Graduação em Ciências Biológicas (Bacharelado), Universidade Federal de Goiás, Campus Jataí. E-mail: <elainefranciely@gmail.com>.

${ }^{3}$ Departamento de Ciências Biológicas, Universidade Federal de Goiás, Campus Jataí. E-mail: < fredericoagg@gmail.com>.

${ }^{4}$ Programa de Pós-graduanda em Produção Vegetal, Universidade Federal de Goiás, Campus Jataí. E-mail: <raquelbioufg@yahoo.com.br>.
} 


\section{INTRODUÇÃO}

A arborização em áreas urbanizadas proporciona uma série de vantagens, como redução dos efeitos da poluição, absorção de parte dos raios solares, proteção contra o impacto direto dos ventos, redução do impacto das gotas da chuva sobre o solo minimizando os processos erosivos - e ornamentação da cidade, além de fornecer abrigo e alimento para a fauna local (MILANO e DALCIN, 2000; SILVA et al., 2002; COSTA et al., 2006).

Geralmente, entretanto, o planejamento urbano deixa de incluir a arborização, permitindo que iniciativas particulares, desprovidas de conhecimento técnico, executem o plantio irregular de espécies, ou seja, sem compatibilidade com o local. Essa situação é traduzida em futuros transtornos à população local, causando prejuízos como rompimento de fiação de energia elétrica e telecomunicação, entupimento de calhas, danos às redes subterrâneas de água e de esgoto, obstáculos para circulação e acidentes envolvendo pedestres, veículos ou edificações (SILVA et al., 2002). Nessa perspectiva, a arborização das cidades brasileiras não tem planejamento prévio, daí a decorrência de sérios problemas de manejo (MALAVASI e MALAVASI, 2001; COSTA et al., 2006). Tais problemas começam ainda na falta de tratos culturais para a produção de mudas destinadas à arborização (GONÇALVES et al., 2004).

Ao longo dos bairros das cidades, a vegetação desempenha diversas funções ligadas e influenciadas por aspectos sociais, culturais, econômicos e ecológicos (GONÇALVES, 1999), interferindo fortemente nas condições de conforto ambiental. É possível que a disparidade econômica em comunidades vizinhas implique arborização diferenciada, podendo ser, na maioria das vezes, incorreta (MILANO, 1998). Portanto, a condição econômica pode ser um dos fatores que influenciam na arborização local e está geralmente associada à falta de informações que as comunidades de baixa renda têm para a execução do plantio, além da escassez de instruções em geral, por parte do poder público, de como manipular o elemento arbóreo após o plantio. Nesse sentido, regiões urbanas de maior poder aquisitivo tendem a possuir melhor adequação da arborização. Além disso, espera-se maior cuidado do poder público nos setores mais nobres da cidade do que naqueles mais periféricos, visto que estes, eventualmente, são destituídos de obras municipais básicas, como calçadas e redes de água e esgoto. Entretanto, não há relatos científicos sobre estudos comparativos dos aspectos da arborização urbana em setores urbanos com diferentes condições socioeconômicas.

Nesse contexto, este estudo teve como objetivo avaliar comparativamente a qualidade e quantidade de espécies arbóreas plantadas no perímetro urbano da cidade de Jataí, Estado de Goiás. Partindo do princípio de que a população com maior poder aquisitivo reside nos padrões de construção civil mais elevado, trabalhou-se com a hipótese de que há maior adequação da arborização urbana nesses setores da cidade do que naqueles com padrões construtivos mais precários.

\section{MATERIAL E MÉTODOS}

\subsection{Caracterização da área}

A cidade de Jataí localiza-se no Sudoeste do Estado de Goiás a cerca de 350 km da capital goiana, apresentando 82.000 habitantes em uma área de 7.174 km² (IBGE Cidades, 2007). Com base nos dados meteorológicos coletados na estação da Universidade Federal de Goiás - Campus Jataí, a temperatura média anual oscila em torno dos $22,2{ }^{\circ} \mathrm{C}$, com máximas médias de $24,4{ }^{\circ} \mathrm{C}$ e mínimas médias de $18,2^{\circ} \mathrm{C}$. A precipitação média anual é de $1.609 \mathrm{~mm}$ (valores correspondentes aos anos de 1980 a 2001), com período chuvoso se estendendo de outubro a abril e período seco correspondente aos meses de junho a agosto. A umidade relativa do ar varia de 49 a 80\% e, embora apresente clima agradável, é fácil notar a presença de árvores plantadas ou podadas inadequadamente ao longo da cidade, o que torna a arborização urbana escassa e necessária, especialmente no verão, que concentra os meses mais quentes do ano.

\subsection{Coleta e análise dos dados}

A avaliação comparativa da arborização urbana foi baseada em um mapeamento georreferenciado contendo todas as quadras da cidade de Jataí, confeccionado por técnicos da Prefeitura em programa AutoCad (Figura 1). Cada quadra foi categorizada pela Prefeitura, segundo o padrão de construção civil das residências e estabelecimentos comerciais. Vários quesitos foram considerados para estabelecer esses padrões, com base em um boletim cadastral de registro das características do lote (como tamanho, inclinação do terreno, calçada, pavimentação asfáltica, redes de água, esgoto, elétrica e telefone, coleta de lixo) e do 
tipo da edificação (como muro, alvenaria, laje, telhado, esquadrias), os quais refletiram nos valores diferenciados de impostos prediais, territoriais e urbanos (IPTU).

A Prefeitura, dessa forma, subdividiu todo o perímetro urbano da cidade em quatro categorias distintas: alto, médio, simples e precário. Os padrões alto e médio foram considerados como categoria única neste estudo, pois compreenderam apenas 4 e 74 quadras ( $0,2 \%$ e $4,2 \%$ do total), respectivamente. Portanto, o estudo trabalhou com três categorias de acordo com o padrão de construção civil adotado: 1 . alto/médio, 2. simples e 3. precário. Para cada uma foi analisada a arborização urbana de 60 quadras, escolhidas de forma casualizada e independente do bairro, totalizando 180 quadras avaliadas ao longo da cidade. Edificações públicas, como praças e parques, não foram classificadas pela Prefeitura e, portanto, não consideradas aqui. Os dados foram coletados entre abril e setembro de 2007.

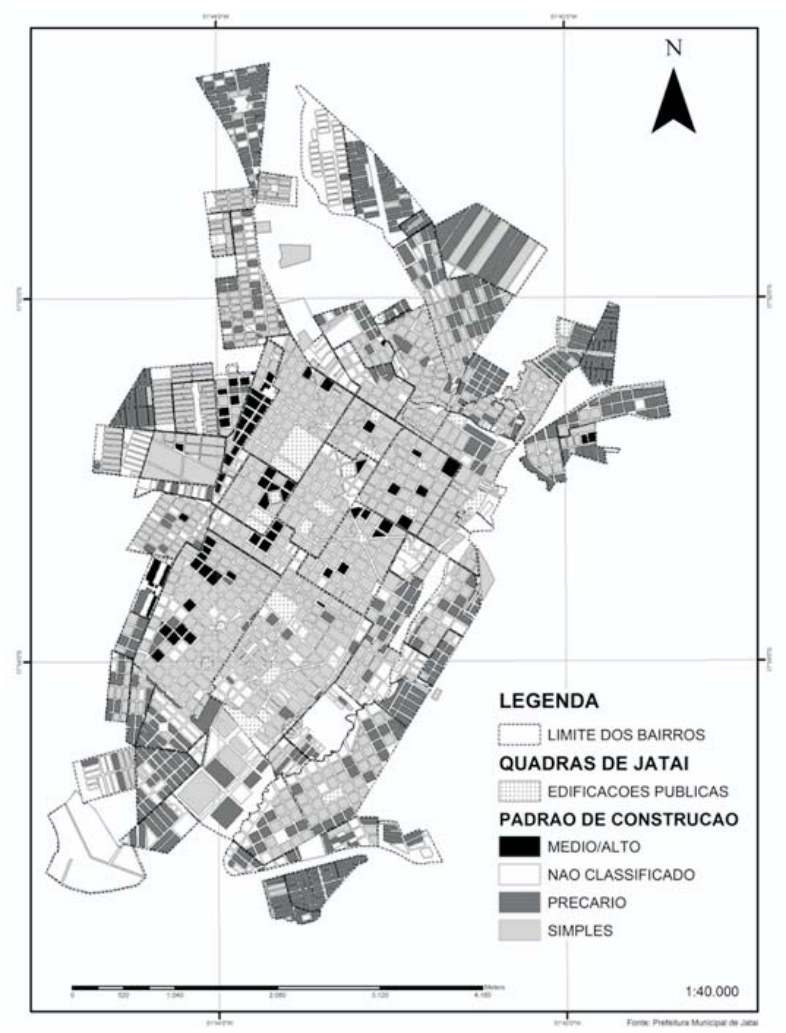

Figura 1 - Mapa georreferenciado de todas as quadras da cidade de Jataí, subdivididas em: padrão alto/médio, simples e precário.

Figure 1 - Georeferenced map of all blocks of Jataí city, partitioned in: high/medium, simple and precarious patterns.
Foram realizados a observação e o registro fotográfico das árvores previamente indeterminadas, presentes nas calçadas das quadras. Os indivíduos arbóreos plantados foram identificados e tiveram registradas informações como: 1 . porte arbóreo (pequeno - em geral, espécies que não ultrapassam 6 m de altura, ou médio/grande porte - em geral espécies arbóreas com mais de $6 \mathrm{~m}$ ), possibilitando avaliar se a planta é indicada ou não para a arborização urbana; 2 . fitossanidade (sadia, doente ou com poda radical); 3. local do plantio (em frente à residência ou comércio/ indústria); 4. posição na calçada (meio-fio, centro ou parede), possibilitando avaliar a interferência do tronco ou ramos da árvore no trânsito de pedestres, e 5. origem (exótica ou nativa do bioma Cerrado). Também, foram registradas informações sobre a existência de calçamento adequado e asfalto nas quadras amostradas em cada categoria.

O número de árvores plantadas por quadra e o número de espécies arbóreas levantadas em cada uma das categorias foram registrados. Isso possibilitou, junto com as demais informações relacionadas anteriormente, analisar estatisticamente os dados. Assim, foram realizadas análises de qui-quadrado $\left(c^{2}\right)$, com base em frequência de ocorrência, além de análises de variância (ANOVA), baseando-se em comparação de médias entre as três categorias.

\section{RESULTADOS}

Baseado no mapa confeccionado pela Prefeitura, Jataí possui 652 quadras no padrão precário, 1.041 no padrão simples e 78 no padrão alto/médio, totalizando 1.771 quadras. Desse total, foram avaliados 10,2\% da arborização urbana da cidade, sendo registrado um total de 1.953 árvores: 511 no padrão precário, 724 no padrão simples e 718 no padrão alto/médio. Com esses valores, foi possível realizar estimativa do número total de árvores plantadas em toda a cidade. Assim, estimaramse 5.553 árvores no padrão precário, 12.561 no padrão simples e 933 no padrão alto/médio, totalizando 19.048 árvores plantadas na cidade para fins de arborização urbana. Isso sem considerar parques, praças, canteiros centrais de avenidas e outras áreas arborizadas.

As 1.953 árvores distribuíam-se em 114 espécies, e apenas 10 delas totalizaram 71,2\% do total de indivíduos. Ocorreram 50 espécies com apenas um ou dois indivíduos nas três categorias avaliadas. Apenas sete quadras não tiveram plantas registradas (seis no padrão precário

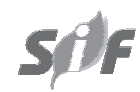

R. Árvore, Viçosa-MG, v.34, n.2, p.287-295, 2010 
e uma no padrão simples). O número médio de árvores não variou significativamente entre o padrão alto/médio e simples, baseado no teste de ANOVA (Tabela 1). Entretanto, o padrão precário apresentou número médio de árvores significativamente menor quando comparado aos padrões alto/médio e simples.

A Tabela 2 mostra a lista das 50 espécies mais utilizadas na arborização da cidade. A espécie mais plantada foi o oiti, contribuindo com 30,9\% de todos os indivíduos registrados, seguida do chorão e da quaresmeira, todas mais abundantes no padrão alto/ médio. Embora seja uma liana, a espécie jasmimda-índia foi considerada no estudo devido à sua ampla utilização. Essa espécie foi encontrada com frequência no padrão simples (38,3\% do total dos indivíduos), mas ocorreu principalmente no padrão precário (53,2\% do total dos indivíduos). Embora normalmente apresentem porte arbustivo, indivíduos da espécie pingo-de-ouro não submetidos à poda foram considerados no estudo, já que apresentavam fuste único e lenhoso, mostrando, portanto, porte arbóreo.

No estudo foram encontradas várias espécies frutíferas, as quais representaram 8,4\% da arborização total, com predomínio no padrão precário (14\% do total dos indivíduos). Além disso, espécies de grande porte e, portanto, menos indicadas para a arborização como o flamboyant e sete-copas foram encontradas em maior número no padrão precário. No entanto, espécies de pequeno e médio portes como pingode-ouro, quaresmeira, flamboyant-mirim e escovade-garrafa foram mais frequentes no padrão alto/ médio (Tabela 2). Da mesma forma, $74,1 \%$ das oito espécies de palmeiras registradas em todo o levantamento foram registradas no padrão alto/médio.

Das 1.953 árvores registradas, 99\% foram plantadas em frente às residências. No total, 1.853 são árvores exóticas, correspondendo a 81,5\% do total de espécies.
A frequência de plantas utilizadas na arborização entre as três categorias, em função da origem exótica, não mostrou diferença significativa através do teste de $\chi^{2}$. Ao passo que as espécies nativas tiveram número de árvores abaixo e acima do esperado nos padrões alto/médio e precário $\left(\chi^{2}=19,32 ; P<0,001\right)$, respectivamente.

$O$ teste de $\chi^{2}$ também mostrou diferenças significativas na frequência de árvores entre as três categorias em função da posição na calçada (Tabela 3). O padrão alto/médio teve um número de árvores acima e abaixo do esperado $(P<0,001)$ no meio-fio e no centro da calçada, respectivamente. Ao passo que o padrão precário mostrou resultados significativamente opostos $(P<0,001)$. Os dados também demonstraram as más condições de calçamento e infraestrutura no padrão precário, em que apenas 74,5\% das ruas eram asfaltadas e $48,8 \%$ possuíam calçadas. Ao passo que no padrão alto/médio 92,7\% das ruas eram asfaltadas e 91,8\% possuíam calçamento.

Com relação ao posicionamento, não houve diferenças significativas entre as duas situações avaliadas. Foram registrados 1.088 dos indivíduos plantados livres (55,7\%) e 865 sob a rede elétrica (44,3\%). Quando comparado com o porte, os indivíduos de médio a grande porte totalizaram $68,8 \%$, que se localizados sob rede elétrica podem causar problemas. Nessa classe, as principais espécies foram: oiti, fícus-benjamina, setecopas e monguba, respectivamente com 604, 101, 82 e 63 indivíduos.

A análise de sanidade registrou apenas 21 indivíduos (1,1\% do total) com algum tipo de doença. A observação sobre poda (correta e incorreta) ocorreu de maneira um pouco subjetiva, já que algumas podas que reduziam o porte ou compatibilizavam os indivíduos com a infraestrutura urbana, especialmente com redes elétricas e telefônicas, foram consideradas corretas. Nesse caso, apenas $0,2 \%$ mostrou-se incorreta ou foi sujeita à poda radical.

Tabela 1 - Valores médios \pm desvios-padrão de cada uma das três categorias avaliadas na cidade de Jataí, GO. Análises de variância (ANOVA) com diferenças médias significativas entre as categorias são seguidas de letras diferentes, baseadas em testes de Tukey.

Table 1 - Average values \pm standard errors of each category evaluated in Jataí city, GO. Different letters between categories indicate significant differences in ANOVA, by Tukeys'test.

\begin{tabular}{|c|c|c|c|c|c|c|c|}
\hline \multirow[b]{2}{*}{$F_{(2,177)}$} & \multirow[b]{2}{*}{$P$} & \multicolumn{6}{|c|}{ Categorias } \\
\hline & & & & & & & \\
\hline 4,96 & 0,008 & $12,0 \pm 8,0$ & $\mathrm{a}$ & $12,1 \pm 6,6$ & $\mathrm{a}$ & $8,5 \pm 6,4$ & b \\
\hline
\end{tabular}

R. Árvore, Viçosa-MG, v.34, n.2, p.287-295, 2010 
Tabela 2 - Cinquenta espécies mais frequentes registradas na arborização urbana de 180 quadras da cidade de Jataí, GO. 1. Padrão alto/médio; 2. Padrão simples; 3. Padrão precário. Po: porte (p: pequeno/m: médio/g: grande). * Espécies nativas.

Table 2 - Fifty most frequent species found in urban planting of 180 blocks in Jataí city, GO. 1. High/medium pattern; 2. Simple pattern; 3. Precarious pattern. Po: tree weight (p: small / m: medium / g: large). * native species.

\begin{tabular}{|c|c|c|c|c|c|c|}
\hline Nome Científico & Nome vulgar & 1 & 2 & 3 & Total & Po \\
\hline Licania tomentosa (Benth.) Fritsch & oiti & 268 & 228 & 108 & 604 & $\overline{\mathrm{m}}$ \\
\hline Schinus molle L. & chorão & 73 & 42 & 4 & 119 & $\mathrm{p}$ \\
\hline Tibouchina granulosa (Desr.) Cogn. & quaresmeira & 70 & 29 & 9 & 108 & $\mathrm{~m}$ \\
\hline Quisqualis indica L. & jasmim-da-índia & 9 & 41 & 57 & 107 & $\mathrm{p}$ \\
\hline Ficus benjamina L. & ficus-benjamina & 33 & 48 & 20 & 101 & $\mathrm{~m}$ \\
\hline Terminalia catappa L. & sete-copas & 8 & 40 & 34 & 82 & $\mathrm{~m}$ \\
\hline Murraya paniculata (L.) Jack. & murta & 17 & 33 & 31 & 81 & $\mathrm{p}$ \\
\hline Duranta repens L. var. aurea Hort. & pingo-de-ouro & 28 & 26 & 27 & 81 & $\mathrm{p}$ \\
\hline Paquira aquatica Aubl. & monguba & 18 & 24 & 21 & 63 & $\mathrm{~m}$ \\
\hline Psidium guajava L. * & goiabeira & 6 & 20 & 19 & 45 & $\mathrm{p}$ \\
\hline Callistemon viminalis (Sol. Ex Gaertn.) G. Don ex Loud. & escova-de-garrafa & 27 & 9 & 0 & 36 & $\mathrm{~m}$ \\
\hline Dypsis cf cabadae H. E. Moore & palmeira-de-cadaba & 22 & 2 & 0 & 24 & $\mathrm{~m}$ \\
\hline Tabebuia cf pentaphylla Hemsl. & ipê-bálsamo & 10 & 6 & 4 & 20 & g \\
\hline Bauhinia cf. blakeana Dunn. & pata-de-vaca & 6 & 11 & 3 & 20 & $\mathrm{~m}$ \\
\hline Caesalpinia pluviosa DC. & sibipiruna & 8 & 4 & 8 & 20 & g \\
\hline Dyptis lutescens H. Wendl. & areca-bambu & 6 & 6 & 7 & 19 & $\mathrm{~m}$ \\
\hline Nerium oleander L. & espirradeira & 3 & 6 & 10 & 19 & $\mathrm{p}$ \\
\hline Mangifera indica L. & mangueira & 3 & 9 & 7 & 19 & g \\
\hline Carica papaya $\mathrm{L}$. & mamão & 2 & 6 & 9 & 17 & $\mathrm{p}$ \\
\hline Muntingia calabura L. & calabura & 0 & 5 & 10 & 15 & $\mathrm{~m}$ \\
\hline Myroxylon peruiferum L. f. & bálsamo & 2 & 6 & 5 & 13 & $\mathrm{~m}$ \\
\hline Anacardium occidentale L. * & cajueiro & 0 & 9 & 4 & 13 & $\mathrm{~m}$ \\
\hline Tecoma stans (L.) Juss. ex Kunth & ipê-amarelo-de-jardim & 8 & 2 & 3 & 13 & $\mathrm{p}$ \\
\hline Senna siamea (Lam.) H.S. Irwin \& R.C. Barneby & cássia & 4 & 6 & 0 & 10 & $\mathrm{~m}$ \\
\hline Citrus limonia Osbeck & limão-china & 2 & 6 & 2 & 10 & $\mathrm{p}$ \\
\hline Malpighia emarginata Sessé \& Moc. ex DC. & acerola & 1 & 5 & 3 & 9 & $\mathrm{p}$ \\
\hline Cycas circinalis Roxb. & cicas & 9 & 0 & 0 & 9 & $\mathrm{p}$ \\
\hline Dracaena cf arborea (Willd.) Link & dracena-arbórea & 7 & 2 & 0 & 9 & $\mathrm{~m}$ \\
\hline Caesalpinia pulcherrima (L.) Sw. & flamboyan-mirim & 5 & 3 & 1 & 9 & $\mathrm{p}$ \\
\hline Delonix regia (Bojer ex Hook.) Raf. & flamboyant & 0 & 3 & 6 & 9 & g \\
\hline Leucaena leucocephala (Lam.) R. de Wit & leucena & 0 & 4 & 5 & 9 & $\mathrm{~m}$ \\
\hline Sabal maritima (H.B.\& K.) Burret & sabal-de-cuba & 9 & 0 & 0 & 9 & $\mathrm{~m}$ \\
\hline Calliandra brevipes Benth. & esponja & 1 & 1 & 6 & 8 & $\mathrm{~m}$ \\
\hline Syzygium malaccense (L.) Merr. \& L.M. Perry & jambo-vermelho & 0 & 5 & 3 & 8 & $\mathrm{~m}$ \\
\hline Leea rubra Blume & léia & 8 & 0 & 0 & 8 & $\mathrm{p}$ \\
\hline Inga cf edulis Mart. * & angá & 1 & 2 & 4 & 7 & $\mathrm{~m}$ \\
\hline Leea coccinea Planch. & léia & 7 & 0 & 0 & 7 & $\mathrm{p}$ \\
\hline Citrus latifolia Tanaka & limão-taiti & 0 & 3 & 4 & 7 & $\mathrm{p}$ \\
\hline Eriotheca gracilipes (K. Schum.) A. Rob. * & paineirinha-do-cerrado & 0 & 7 & 0 & 7 & $\mathrm{~m}$ \\
\hline Caryocar brasiliense Cambess. * & pequi & 0 & 5 & 2 & 7 & $\mathrm{~m}$ \\
\hline Lagerstroemia indica $\mathrm{L}$. & resedá & 4 & 0 & 3 & 7 & $\mathrm{~m}$ \\
\hline Morus nigra L. & amoreira & 0 & 2 & 4 & 6 & $\mathrm{~m}$ \\
\hline Erythrina indica Lam. var. picta Hort. & eritrina-variegada & 0 & 1 & 5 & 6 & $\mathrm{~m}$ \\
\hline Tabebuia cf impetiginosa (Mart.) Standl. * & ipê-roxo & 6 & 0 & 0 & 6 & g \\
\hline Manihot esculenta Crantz & mandioca & 0 & 0 & 6 & 6 & $\mathrm{p}$ \\
\hline Jatropha sp & pinhão-roxo & 0 & 2 & 4 & 6 & $\mathrm{p}$ \\
\hline Euphorbia leucocephala Lotsy & cabeleira-de-velho & 0 & 2 & 3 & 5 & $\mathrm{p}$ \\
\hline Spondias dulcis Parkinson & cajá-manga & 0 & 2 & 3 & 5 & g \\
\hline Cassia fistula L. & cássia-imperial & 3 & 0 & 2 & 5 & $\mathrm{~m}$ \\
\hline Syagrus oleracea (Mart.) Весc. * & gueiroba & 1 & 1 & 3 & 5 & $\mathrm{~m}$ \\
\hline
\end{tabular}


Tabela 3 - Distribuição de frequência de árvores nas três categorias em relação ao posicionamento na calçada, Jataí, GO. Obs.: frequência observada. Esp: frequência esperada.

Table 3 - Tree frequency distribution for the three categories in sidewalk positioning, Jataí, GO. Obs: observed frequency. Esp: expected frequency.

\begin{tabular}{|c|c|c|c|c|c|c|c|c|c|}
\hline & \multicolumn{2}{|c|}{ Alto/Médio } & \multicolumn{2}{|c|}{ Simples } & \multicolumn{2}{|c|}{ Precário } & \multirow[b]{2}{*}{ Soma } & \multirow[b]{2}{*}{$\chi^{2}$} & \multirow[b]{2}{*}{$P$} \\
\hline & obs & esp & obs & esp & obs & esp & & & \\
\hline Centro & 77 & 251 & 285 & 253 & 320 & 187 & 682 & 235,15 & $<0,001$ \\
\hline Meio-fio & 574 & 373 & 366 & 376 & 75 & 266 & 1015 & 243,86 & $<0,001$ \\
\hline Parede & 67 & 94 & 73 & 95 & 116 & 67 & 256 & 47,50 & $<0,001$ \\
\hline Totais & 718 & 718 & 724 & 724 & 511 & 511 & 1953 & & \\
\hline
\end{tabular}

\section{DISCUSSÃO}

O grande número de espécies levantado na arborização da cidade de Jataí (114) pode ser proveniente de plantios contínuos e aleatórios, realizados pela própria população local. Entretanto, mesmo que esse elevado número de espécies tenha sido gerado de forma não propositada na cidade, a maior diversidade de espécies de árvores na paisagem urbana se faz necessária, justamente para garantir o máximo de proteção contra infestações generalizadas de pragas e doenças (MELO et al., 2007).

Segundo recomendações de Grey e Deneke (1986), cada espécie não deve ultrapassar 15\% do total de indivíduos plantados, visando ao bom planejamento da arborização urbana. Nesse aspecto, o predomínio de indivíduos de oiti plantados na cidade de Jataí sai das recomendações desses autores. Costa e Higuchi (1999), Silva et al. (2002) e Silva Filho (2002) também registraram predomínio dessa espécie nas cidades de Manaus (AM), Uberlândia (MG) e Jaboticabal (SP), contribuindo com 29\%, 32\% e 22\% da arborização total dessas cidades, respectivamente. Isso demonstra que a espécie é amplamente difundida e bem aceita na arborização urbana em determinadas regiões brasileiras. Embora em algumas situações o oiti se torne de médio a grande porte, os aspectos benéficos são mais visíveis, sendo uma espécie com folhas perenes, proporciona boa sombra e não danifica o calçamento.

A grande quantidade de indivíduos arbóreos plantados na frente de residências pode ser justificada por ser um local mais adequado do que em frente de comércios, hotel e outros, devido ao fato de a copa das árvores permitirem menor destaque e visualização de placas e luminosos comerciais e industriais.

Segundo Mendonça (2000), as principais espécies arbóreas plantadas nos logradouros públicos de Uberlândia (passeios e canteiros centrais das avenidas) são ficus-benjamina, sibipiruna, sete-copas, monguba, flamboyant, oiti e magnólia. Em Jataí, algumas dessas espécies se mostraram conflitantes, especialmente ficusbenjamina, sete-copas e flamboyant. O número elevado de indivíduos de ficus-benjamina registrados neste estudo se justifica, provavelmente, pelo modismo e por estímulo do seu plantio em gestões municipais pretéritas. Isso poderá acarretar danos estruturais e sérios prejuízos futuros à cidade. Santana e Santos (1999) afirmaram que o gênero Ficus é causador de problemas como elemento de arborização, por danificarem calçadas e apresentarem grande potencial de conflitos futuros com redes de serviço e construções. Sete-copas é outra espécie que possui folhas grandes, que nos meses de julho e agosto se desprendem das árvores, sujando as calçadas e ruas, além de causarem entupimento da rede pluvial. Flamboyant também não é indicado para arborização de ruas, por apresentar raízes superficiais que podem danificar as calçadas. Além disso, Coutinho et al. (1998) constataram a presença marcante do Cerambicídeo Oncideres saga, conhecido como serrador, em árvores de flamboyant na arborização do Campus da Universidade Federal Rural do Rio de Janeiro. Todas essas espécies também foram citadas por Rocha et al. (2004) como inapropriadas para a arborização de vias públicas devido à inadequação com as obras urbanas civis.

Neste estudo, observaram-se várias árvores em contato atual ou potencial com a rede elétrica, indicando a ocorrência de podas para redução do porte e seus possíveis efeitos deletérios ao vigor e estrutura do indivíduo, além da poluição visual gerada. Isso pode acarretar também sérios danos aos moradores. Sanchotene (1990) argumentou que os trabalhos de podas anuais sucessivas ao longo do tempo danificam muito a arborização de modo geral. Preocupam, ainda, os trabalhos realizados na vegetação que visam compatibilizá-la com a infraestrutura urbana, 
especialmente com redes elétrica e telefônica. Sugere-se que haja soluções alternativas para tais fatos na falta de uma orientação correta sobre o plantio. Nesse sentido, pode ser realizado isolamento ou proteção da fiação elétrica, modificações na disposição dos fios e dos postes, modificações nos sistemas de iluminação pública e troca da fiação aérea pela subterrânea. Essas são, enfim, medidas que fazem parte de um planejamento de instalação de novos equipamentos urbanos de forma a permitir a existência da arborização (MILANO e DALCIN, 2000).

Com relação à ornamentação e amenização climática em frente às residências, a variação do número médio de árvores mostrou maior preocupação de moradores nas quadras estudadas de padrão alto/médio do que moradores de quadras do padrão precário. As más condições do calçamento ou falta de infraestrutura nas quadras do padrão precário podem ter contribuído para menor número de árvores plantadas nessa categoria, incentivadas pelo desestímulo ou, mesmo, impossibilidade dos residentes de plantar árvores em frente às suas casas. Os dados obtidos em função da posição nas calçadas reforçam os problemas encontrados na adequação do plantio em calçadas das quadras do padrão precário na cidade de Jataí. A correta arborização urbana deve sempre ser feita junto ao meio-fio do calçamento, no sentido de otimizar o fluxo de pedestres. Ou, ainda, dependendo da espécie e da largura da calçada, a arborização pode ser feita satisfatoriamente no limite do lote com a calçada.

A espécie jasmim-da-índia foi bem comum no padrão precário (11,1\% dos indivíduos) e é usada principalmente na formação de caramanchões na frente das casas. Pode-se supor que o menor tamanho de lotes e casas nessa categoria faz que seus moradores utilizem esses caramanchões como varanda alternativa, o que funcionaria como uma “extensão da residência” e serviria para amenizar a temperatura nos dias mais quentes. Outro aspecto que merece ressalva foi a grande quantidade de espécies frutíferas encontradas no padrão precário (14\% de espécies frutíferas). Portanto, sugere-se que há provável preferência dos moradores dessas localidades em cultivar espécies arbóreas que irão gerar não só ornamentação, mas também algum tipo de alimento. Essa característica pode acarretar problemas, já que árvores de médio a grande porte com incidência de frutos volumosos podem apresentar perigo de queda nos veículos, edificações e, principalmente, nos pedestres.
Foi observada maior quantidade de espécies exóticas neste estudo. Klein (1985) afirmou que o sucesso obtido, por meio da introdução das espécies exóticas, se deve a fatores como a adequada seleção das espécies, metodologia silvicultural desenvolvida e grande facilidade de coleta de sementes. No entanto, esse mesmo autor recomendou que as espécies nativas seriam mais adequadas para manter a dinâmica do solo e o clima regional. O uso de espécies arbóreas nativas na arborização urbana ainda não se constitui prática comum nos processos de planejamento urbano. A presença dessas em maior quantidade no padrão precário pode ser justificada por serem provenientes de plantios aleatórios, não havendo seleções de espécies adequadas à arborização. Em Brasília, os novos plantios têm priorizado as espécies nativas da região, sendo essa prática recomendada por Rodrigues et al. (1994) e já adotada no Campus da Universidade de Brasília (KUNIHARA et al., 2005).

A grande porcentagem das palmeiras registradas no padrão alto/médio evidencia, no entanto, maior adequação no plantio e melhores condições de elaboração de um paisagismo nesses setores da cidade, proporcionado por melhor renda per capita da população nessas quadras de Jataí. Em geral, palmeiras são bastante ornamentais e apropriadas ao paisagismo e à arborização urbana, sendo encontradas em viveiros por preços muitas vezes pouco acessíveis, dependendo do porte da planta e da espécie.

De maneira geral, visualmente hoje é nítida a carência ou a inadequação de árvores plantadas em alguns setores da cidade de Jataí. Portanto, a intervenção de profissionais capacitados pode tornar a realização de programas de arborização urbana mais eficiente. Dessa forma, erros como esses encontrados não só no atual estudo, mas também em outras áreas urbanizadas, poderão ser diminuídos. A participação incipiente da comunidade nos programas de arborização de ruas, além da falta de conscientização sobre a importância das árvores no ambiente urbano, gera sérios prejuízos aos plantios de árvores de ruas (MALAVASI e MALAVASI, 2001; COSTA et al., 2006; VOLPE-FILIK et al., 2007).

\section{CONCLUSÕES}

- O oiti foi a espécie mais abundante do estudo e, junto com várias outras encontradas com frequência, retrata a grande quantidade de indivíduos e espécies exóticas plantados na cidade de Jataí.

R. Árvore, Viçosa-MG, v.34, n.2, p.287-295, 2010 
- O estudo constatou diferenças na quantidade e qualidade das árvores plantadas em quadras de diferentes padrões construtivos. Entre os vários parâmetros avaliados, os padrões alto/médio e precário mostraram-se mais divergentes, enquanto o padrão simples, em geral, mostrou características intermediárias na arborização urbana de Jataí. O padrão alto/médio teve maior número médio de árvores, menor número de indivíduos de médio e grande portes e plantio mais adequado em relação à posição na calçada do que o padrão precário.

- Os resultados podem subsidiar técnicos da Prefeitura Municipal de Jataí, bem como a população, no sentido de instruir desde a melhor forma de plantio e escolha de mudas apropriadas até a manutenção delas após a maturação.

- Recomenda-se a introdução de espécies nativas aptas à arborização, principalmente em quadras desprovidas de árvores e em futuras áreas urbanas. Recomenda-se ainda a eventual substituição de árvores, como ficus-benjamina, na intenção de evitar problemas urbanos futuros.

\section{AGRADECIMENTOS}

À PRPPG/UFG (Edital 02-2006), do auxílio financeiro para a execução do estudo; a Prefeitura Municipal de Jataí, por disponibilizar o mapa da cidade de Jataí com os padrões construtivos; ao Manoel Neto, pelo valioso auxílio na elaboração do mapa georreferenciado; e a Kaila Ressel, Cláudia Scareli e revisores anônimos, pelas valiosas críticas e contribuições ao manuscrito.

\section{REFERÊNCIAS}

COSTA, L. A. et al. Avaliação das áreas verdes públicas da cidade de Manaus: situação em 1991.

Caminhos de Geografia, v.6, n.19, p.1-10, 2006.

COSTA, L. A. C.; HIGUCHI, N. Arborização de ruas de Manaus: avaliação qualitativa e quantitativa.

Revista Árvore, v.23, n.2, p.223-232, 1999.

COUTINHO, C. L. et al. Oncideres saga (Dalman, 1823) (Coleoptera, Cerambycidae) e a arborização urbana em Seropédica, RJ. Floresta e Ambiente, v.51, n.1, p.50-54, 1998.

GONÇALVES, E. O. et al. Avaliação qualitativa de mudas destinadas à arborização urbana no Estado de Minas Gerais. Revista Árvore, v.28, n.4, p.479-486, 2004.

R. Árvore, Viçosa-MG, v.34, n.2, p.287-295, 2010
GONÇALVES, W. Florestas urbanas. Revista Ação Ambiental, v.9, n.1, p.17-19, 1999.

GREY, G. W.; DENEKE, F. J. Urban forestry. New York, John Wiley \& Sons, 1986. 279p.

IBGE Cidades, 2007. Disponível em: <http:// www.ibge.gov.br>. Acesso em: 15 dez. 2007.

KLEIN, R. M. Síntese ecológica da floresta estacional da Bacia do Jacuí: importância do reflorestamento com essências nativas (RS). In: CONGRESSO FLORESTAL ESTADUAL, 5., 1985, Nova Prata. Anais... Nova Prata: PMNP, 1985. p.265-278.

KUNIHARA, D. L.; IMAÑA-ENCINAS, J.; PAULA, J. E. Levantamento da arborização do campus da Universidade de Brasília. Revista Cerne, v.11, n.2, p.127-136, 2005.

MALAVASI, U. C.; MALAVASI, M. M. Avaliação da arborização urbana pelos residentes - estudo de caso em Mal. Cândido Rondon, Paraná.

Ciência Florestal, v.11, n.1, p.189-193, 2001.

MELO, R. R.; LIRA FILHO, J. A.; JÚNIOR, R. F. Diagnóstico qualitativo e quantitativo da arborização urbana no bairro Bivar Olinto, Patos, Paraíba. Revista da Sociedade Brasileira de Arborização Urbana, v.2, n.1, p.64-80, 2007.

MENDONÇA, M. G. Políticas e condições ambientais de Uberlândia - MG no contexto estadual e federal. 2000. Dissertação (Mestrado em Geografia) Universidade Federal de Uberlândia, Uberlândia, 2000. 84p.

MILANO, M. S. Curso sobre arborização urbana. LOCAL: Universidade Livre do Meio Ambiente, 1998.

MilAnO, M. S.; DALCIN, E. C. Arborização de vias públicas. Rio de Janeiro: Light, 2000. 226p.

ROCHA, R. V.; LELES, P. S. S.; NETO, S. N. O. Arborização de vias públicas em Nova Iguaçu, RJ: o caso dos bairros Rancho Novo e Centro.

Revista Árvore, v.28, n.4, p.599-607, 2004. 
RODRIGUES, M. G. R.; BREDT, A.; UIEDA, W. Arborização de Brasília, Distrito Federal, e possíveis fontes de alimentos para morcegos fitófagos. In: CONGRESSO BRASILEIRO DE ARBORIZAÇÃO URBANA, 2.; ENCONTRO NACIONAL SOBRE ARBORIZAÇÃO URBANA, 5., 1994, São Luís. Anais...São Luís: Sociedade Brasileira de Arborização Urbana, 1994. p.311-318.

SANCHOTENE, M. C. C. Situação das áreas verdes e da arborização urbana em Porto Alegre. In: ENCONTRO NACIONAL SOBRE ARBORIZAÇÃO URBANA, 3., 1990, Curitiba. Anais... Curitiba: FUPEF, 1990. 34-40.

SANTANA, J. R. F.; SANTOS, G. M. M. Arborização do campus da UEFS: exemplo a ser seguido ou um grande equívoco? Sitientibus, n.20, p.103-107, 1999.
SILVA, E. M. et al. Estudo da arborização urbana do Bairro Mansur na cidade de Uberlândia-MG. Caminhos de Geografia, v.3, n.5, p.73-83, 2002.

SILVA FILHO, D. F. Cadastramento informatizado, sistematização e análise da arborização das vias públicas da área urbana do município de Jaboticabal, SP. 81f. Dissertação (Mestrado em Geografia). Universidade Estadual Paulista, Jaboticabal, 2002.

VOLPE-FILIK, A.; SILVA, L. F.; LIMA, A. M. L. P. Avaliação da arborização de ruas do bairro São Dimas na cidade de Piracicaba/SP através de parâmetros qualitativos. Revista da Sociedade Brasileira de Arborização Urbana, v.2, n.1, p.1-10, 2007. 